University of Wollongong

Research Online

Faculty of Engineering and Information

Faculty of Engineering and Information

Sciences - Papers: Part B

Sciences

2019

Prediction of blast furnace hearth condition: part II - a transient state simulation of hearth condition during blast furnace shutdown

Xue Feng Dong

University of Wollongong, xuefeng@uow.edu.au

Paul Zulli

University of Wollongong, paulz@uow.edu.au

Mark Biasutti

BlueScope Steel Limited, mmb784@uow.edu.au

Follow this and additional works at: https://ro.uow.edu.au/eispapers1

Part of the Engineering Commons, and the Science and Technology Studies Commons

Research Online is the open access institutional repository for the University of Wollongong. For further information contact the UOW Library: research-pubs@uow.edu.au 


\title{
Prediction of blast furnace hearth condition: part II - a transient state simulation of hearth condition during blast furnace shutdown
}

\author{
Abstract \\ The extent of hearth cooling is critically important in determining the feasible duration of an extended \\ blast furnace maintenance shutdown. Based on a fixed domain method, a transient numerical model has \\ been developed which considers the effect of solidification enthalpy of liquid iron in a coke-free bath, \\ enabling the progress of hearth cooling to be monitored. The model was initially verified by comparing \\ calculations with actual refractory temperatures during shutdowns of shorter duration (typically 1-2 days) \\ at BlueScope's No. 5 Blast Furnace. It was then applied to estimate the hearth condition during an \\ extended shutdown period (typically, 5-6 days). The calculated refractory temperature differences were \\ reasonably matched with the measured data over the extended shutdown period. This allowed \\ visualization of the temporal variation of refractory temperatures and the extent of liquid bath cooling \\ during extended shutdowns, providing useful guidance for furnace engineers. \\ Disciplines \\ Engineering | Science and Technology Studies

\section{Publication Details} \\ Dong, X. F., Zulli, P. \& Biasutti, M. (2019). Prediction of blast furnace hearth condition: part II - a transient \\ state simulation of hearth condition during blast furnace shutdown. Ironmaking and Steelmaking, Online \\ First 1-6.
}




\section{Prediction of Blast Furnace Hearth Condition: Part II - A Transient}

State Simulation of Hearth Condition during Blast Furnace Shutdown

X.F. Dong ${ }^{\mathrm{a} *}$, P. Zulli ${ }^{\mathrm{a} *}$ and M. Biasutti ${ }^{\mathrm{b}}$

${ }^{a}$ Formerly of BlueScope when work was undertaken, now of School of Mechanical, Materials, Mechatronic and Biomedical Engineering, University of Wollongong, NSW 2522, Australia

${ }^{b}$ Technology and Planning, BlueScope Ltd, Port Kembla, NSW 2505, Australia

Corresponding authors:

X.F. Dong and P. Zulli

School of Mechanical, Materials, Mechatronic and Biomedical Engineering, University of Wollongong, NSW 2522, Australia

Email: xuefeng.dong@uow.edu.au and paulz@uow.edu.au 


\title{
Prediction of Blast Furnace Hearth Condition - Part II: A Transient State Simulation of Hearth Condition during Blast Furnace Shutdown
}

\begin{abstract}
The extent of hearth cooling is critically important in determining the feasible duration of an extended blast furnace maintenance shutdown. Numerical simulation of hearth cooling is very helpful in providing detailed insight into the internal condition of the hearth during the shutdown, for both the liquid bath and refractory. Based on a fixed domain method, a transient numerical model has been developed which considers the effect of solidification enthalpy of liquid iron in a coke free bath, enabling the progress of hearth cooling to be monitored. The model was initially verified by comparing calculations with actual refractory temperatures during shutdowns of shorter duration (typically 1-2 days) at BlueScope's No. 5 Blast Furnace. It was then applied to estimate the hearth condition during an extended shutdown period (typically, 5-6 days). The calculated refractory temperature differences were reasonably matched with the measured data over the extended shutdown period. In particular, the mushy zone (defined in terms of a temperature range around the $1150^{\circ} \mathrm{C}$ isotherm) was tracked. This allowed visualization of the temporal variation of refractory temperatures and the extent of liquid bath cooling during extended shutdowns, providing useful guidance for furnace engineers. Additionally, the model can be applied more broadly to monitor hearth conditions, such as in the case of an abnormal stoppage of the furnace.
\end{abstract}

Keywords: blast furnace; hearth; numerical model; solidification; furnace shutdown.

\section{Introduction}

During normal blast furnace (BF) operations, heat (enthalpy) is extracted from the hearth refractory sidewall via stave cooling and from the hearth bottom via under-hearth cooling. The temperature distribution can be simulated based on a steady-state numerical model (see Part I [1]). The cooling keeps the refractory and furnace shell below critical temperatures and potentially allows for the formation of a freeze-lining on the refractory surface. However, during BF shutdowns, particularly for an extended time ( 100 hours or more, such as those for BlueScope's No.5 BF in 2014), it is prudent to understand the impact of hearth cooling on the solidification of liquid iron and to attempt to minimise its extent.

In principle, hearth cooling is a typical solidification process. As the liquid temperature drops to the solidification temperature, the liquid phase is transformed into a solid by releasing its latent heat. At a micro-scale, various solidification models have been developed to simulate microstructure formation and evolution, such as phase-field model [2, 3], cellular automaton model [4, 5], volume-of-fluid model [6], and level set model [7]. At a larger length scale, i.e. to analyse macroscopic phase change behaviour and neglect the simulation of any micro-scale grain nucleation or growth, mathematical models developed to solve solidification problems can be divided into two major approaches: the front tracking method [8-10] and the fixed domain method [11-14].

In the front tracking method, temperature distributions of solid and liquid phases are solved separately and the location of the solid/liquid interface is explicitly tracked at 
each time step [8-10]. In the fixed domain method, the temperature fields of the liquid and solid phases are solved together within a computational domain. Compared to the first method, the fixed domain method is simpler and more straightforward, since the phase change interface is implicitly captured and the conservation equations are valid for the entire domain. One of more widely accepted fixed domain methods in industrial application is the enthalpy method [12, 15-17], where a single energy conservation equation is used for the entire domain and the latent heat evolution is considered through use of the total enthalpy. In particular, the solution procedure can be accelerated by an enthalpy-porosity formulation to simulate the mushy zone [18]. Although it is limited to the simulation of a sharp interface, the fixed domain method is of value in practice. At BlueScope's Port Kembla Steelworks, the Coupled Fluid Flow and Refractory Model has been successfully applied for modelling of blast furnace hearth conditions [19-22]. However, extended shutdown periods as noted above were beyond the present experience. Therefore, the fixed domain method for simulating hearth cooling was applied in this study.

The primary objective of the present part is to establish the quantitative relationships which govern the transient heat transfer associated with the solidification of liquid iron in the BF hearth. This paper is organised as follows: Section 2 briefly summarises the governing equations used in the unsteady state numerical model together with the implementation of boundary conditions and the solution set up; Section 3 covers the validation of the current model under $\mathrm{BF}$ conditions and model application to an extended shutdown in 2014 to provide an overview of hearth cooling; conclusions are presented in Section 4.

\section{Mathematical modelling and boundary conditions}

\subsection{Governing equations}

The energy conservation equation used in the simulation is given below,

$$
\frac{\partial(\rho \mathrm{H})}{\partial t}+\nabla \cdot(\rho \boldsymbol{u} \mathrm{H})=\nabla \cdot(\lambda \nabla \mathrm{T})+S
$$

where $\mathrm{H}$ is the total enthalpy of the material, i.e. $\mathrm{H}=h+\Delta \mathrm{H}$, including the sensible $(h)$ and the latent $(\Delta \mathrm{H})$ enthalpies. $\Delta \mathrm{H}$ is an important parameter in determining the influence of solidification, which can be described as a function of the liquid fraction, $f_{l}$ and the latent heat of the material, $L$ :

$$
\Delta \mathrm{H}=f_{l} L
$$

The liquid fraction, $f_{l}$, is given by the following expressions

$$
\begin{array}{ll}
f_{l}=0 & \text { if } \mathrm{T}<\mathrm{T}_{\text {solidus }} \\
f_{l}=\frac{\mathrm{T}-\mathrm{T}_{\text {solidus }}}{\mathrm{T}_{\text {liquidus }}-\mathrm{T}_{\text {solidus }}} & \text { if } \mathrm{T}_{\text {solidus }} \leq \mathrm{T} \leq \mathrm{T}_{\text {liquidus }} \\
f_{l}=1 & \text { if } \mathrm{T}>\mathrm{T}_{\text {liquidus }}
\end{array}
$$

The above expressions guarantee the latent heat of the material is effective in Eq. (1) within the temperature range of $\mathrm{T}_{\text {solidus }} \sim \mathrm{T}_{\text {liquidus }}$.

In the liquid domain, there is no forced convection since the taphole is closed. Further, it is assumed that natural convection is negligible and no other heat sources exist; hence 
both the convective and source terms in Eq. 1 are taken as zero. Heat transfer between liquid and solid iron in the mushy zone and between solid/liquid iron and refractory is through the heat conduction. It is important to note that since natural convection is likely to retard the progress of solidification, neglecting it permits the solution for a more severe and "worse-case" condition.

\subsection{Computational domain and material properties}

BlueScope's No. 5 Blast Furnace was used as the basis for the mathematical model. The hearth of furnace is $\sim 10.6 \mathrm{~m}$ in the inner diameter with 3 tapholes (two are diametrically opposite, with the third at $90^{\circ}$ ). Hearth refractory temperatures are monitored via a considerable number of thermocouples at various elevations and circumferential locations (the so-called long and short thermocouples).

A sector-shaped $\left(10^{\circ}\right)$ geometry of the hearth, as shown in Fig. 1, was considered as the computational domain for the simulation. This geometry was selected in order to improve computational efficiency. Further, the heat transfer in the hearth under shutdown conditions is a typical axi-symmetric problem. The computational domain is composed of a liquid (liquid iron) domain and a solid (refractory) domain. The coke bed was generally ignored in the liquid iron domain. This is because during the extended shutdown period, the burden was run down near to the tuyere level; hence, it would be expected that the coke bed would float close to or even on top of the liquid bath surface. The left-hand side (sidewall) boundary of the domain is at the location of the short sidewall thermocouple (T/C), while the bottom (wall) boundary aligns with the lowest hearth pad thermocouple positions. Temperatures from these thermocouples were used as boundary conditions in the simulation. The central line in Figure 1 is the axis of symmetry. The liquid height above the top of taphole (not shown) is approximately $0.5 \mathrm{~m}$. It is assumed that initially there is no solidified material or build-up on the hearth sidewall and pad surfaces.

Although potential buildup on the hearth lining was not considered in the simulation, the wear of the hearth lining was estimated. The initial refractory geometry used for the simulations is shown in Fig. 1. Compared to the original design geometry, the wear of the sidewall refractory lining was determined to be $160 \mathrm{~mm}$ and $50 \mathrm{~mm}$, for the upper and the lower parts, respectively. The wear of the bottom corner and pad were also estimated.

Material properties used in the simulation are listed in Table 1, including the thermal conductivity, heat capacity and density for the various hearth refractories as well as liquid iron. The property for each part of refractory is the same as that given elsewhere (Table 2 in Part I [1]). Thus, only the range of refractory properties is given in Table 1. Liquid iron is assumed to solidify over a temperature range of $1125^{\circ} \mathrm{C}-1175^{\circ} \mathrm{C}$. This is thought to be realistic given this temperature range covers the eutectic temperature in the iron-carbon phase diagram. The conductivity of liquid iron within the mushy zone is assumed to vary linearly between solidus and liquidus temperatures. The latent heat associated with the phase change is $272000 \mathrm{~J} \cdot \mathrm{kg}^{-1}$.

\subsection{Boundary conditions and computational methodology}

The operational data during one of the normal shutdowns were used to validate the mathematical model. During the simulation, the following boundary conditions were applied:

- The sector's front and back faces were treated as symmetrical planes; 
- The top surface of the liquid iron domain was initially treated as a thermal boundary condition, with a fixed temperature, i.e. $1550^{\circ} \mathrm{C}$; an adiabatic boundary was then used during the transient simulation; and

- The hearth plug temperatures from the lowest thermocouple level were used for hearth bottom wall whilst the temperatures from the sidewall short thermocouples were used for hearth sidewall.

The actual sidewall temperature from the sidewall (short) thermocouples during the normal blast furnace shutdown was used for the transient modelling. Linear extrapolation of the data beyond the shutdown period was also conducted to allow the simulation of hearth cooling for 10 days in total. Figure 2 shows the temperature variations at different levels in the hearth sidewall. For example, for GL+3662 data (refractory temperatures recorded at a level $3.662 \mathrm{~m}$ above Ground Level (GL)), the data were extrapolated from 14/03/13 onwards. Overall, the trends show a gradual temperature decrease. Due to the changes in temperature and flow of the hearth stave cooling water during the shutdowns, the smoothness of the temperature trend was locally affected. Once the trend at the higher level intersected with that at the next level below, the trend of the lower level was applied to both levels. The preliminary simulations in the current study showed that the heat loss through the hearth bottom was much less than that through the sidewall. As such, the plug temperature measured at the start of the shutdown was used for the hearth bottom boundary condition, which was regressed to generate the following correlation,

$$
\mathrm{T}(\text { in } \mathrm{K})=-1.34 \mathrm{r}^{2}-6.441 \mathrm{r}+152.93
$$

where $r$ (in $\mathrm{m}$ ) refers to the radial position in the hearth pad.

ANSYS-CFX (v14.5) was used to solve the governing equations in an unstructured tetrahedral mesh. In order to ensure that the solution of the discretized equations closely approximates the solution of the original equations, a second-order central difference scheme was used for diffusion terms and a second-order implicit time-stepping scheme was applied for the transient term. The criterion for convergence of numerical model is that the root mean square residual of the energy equation is less than $10^{-6}$.

\section{Results and discussion}

\subsection{Typical simulation results and validation}

The $1150^{\circ} \mathrm{C}$ isotherm was chosen to monitor the progress of hearth cooling since this temperature represents the eutectic temperature in iron-carbon phase diagram and the mid-point of temperature range of $1125^{\circ} \mathrm{C}-1175^{\circ} \mathrm{C}$. Figure 3 shows a typical calculation for the evolution of the $1150^{\circ} \mathrm{C}$ isotherm over a 10 -day furnace shutdown. There is no occurrence of liquid iron solidification in the first two days $(d<2)$. The $1150^{\circ} \mathrm{C}$ isotherm starts to move away from the wall after two days, indicating the beginning of solidification. This is consistent with observations during a normal 60hour blast furnace shutdown. Within 10 days, the $1150^{\circ} \mathrm{C}$ isotherm gradually moves towards the centre of the hearth. After 10 days, nearly $50 \%$ of the total hearth volume is shown to be occupied by solidified liquid iron.

The corresponding temperature distributions after Day 5 and Day 10 are shown in Fig. 4. Although there is still a relatively hot core region after Day 5, the hearth centre can be seen to be significantly cooler after Day 10. Although the model predicts that a thick solidification layer can be formed after several days cooling, the temperature difference across the solidified liquid iron is small due to its high conductivity so that a high temperature difference exists between the hot and cold faces of the refractory as shown 
in Fig. 4. Hence, it is expected that with further refractory wear later on in the furnace campaign, the cooling of the hearth will be much faster.

Figure 5 shows the comparison between predicted and measured refractory temperatures at various heights (above GL) of the sidewall during the first 2 days of the normal shutdown. The calculated temperature distributions match the measured temperatures reasonably well. Note that short thermocouples are in line with the sidewall boundary in Fig. 1; long thermocouples are located $100 \mathrm{~mm}$ from the short thermocouples. In practice, most of the sidewall thermocouples in the upper levels (above $7 \mathrm{~m}$ ) are near one of the tapholes and therefore, can be affected by both increased refractory wear at the tapholes and increased sensible refractory heat as a result of the casting of hearth liquids before shutdown. However, these factors have not been taken into account in the simulation. In addition, the calculated results represent the average sidewall temperature around the whole furnace so that the discrepancy between calculated and measured data in the upper part of sidewall is more significant due to the non-uniform circumferential locations of the tapholes. It is also worth noting that refractory bricks of different thermal conductivities in the lower part of sidewall cause a sharp change in the temperature profile Fig. 5(a).

\subsection{Application of the model to an extended shutdown}

This section will introduce the prediction of hearth cooling together with the measurements and observations during an extended shutdown for BlueScope's No. 5 Blast Furnace. The prediction played an important role in understanding the possible extent of liquid iron solidification before the shutdown and monitoring the thermal state of hearth throughout the extended shutdown period to avoid over-cooling of the hearth.

Hearth cooling in terms of the evolution of $1150{ }^{\circ} \mathrm{C}$ isotherm. Figure 6 shows the simulated evolution of the $1150{ }^{\circ} \mathrm{C}$ isotherm in the hearth during the first 6 days of the furnace shutdown. As mentioned, the simulation was based on boundary conditions from an earlier but shorter shutdown. A plausible modelling scenario has been chosen for defining the boundary conditions, viz. there is no heat loss from the liquid surface, no coke bed in the liquid bath, and the minimum sidewall temperature at short thermocouple positions set at $45^{\circ} \mathrm{C}$. As discussed previously, Figure 6 indicates there is no occurrence of liquid iron solidification in the first two days. Once the solidification starts, the isotherm moves mainly horizontally, which is driven by the greater heat loss through the sidewall of through the hearth pad. After 100 hours of the shutdown, the model indicates that a layer of liquid iron solidification has been formed (Day 4 isotherm), the volume of which is less than $10 \%$ of the total internal hearth volume. Since there was no direct measurement of the solidification layer, verification of the predicted evolution was done via observations of conditions at furnace start-up and measured refractory temperature during the shutdown, which are discussed subsequently.

Heat flux through the hearth bottom. Figure 7 shows the variation of the temperature difference between the central plug temperatures at two elevations during the shutdown. The locations of thermocouples (GL+3907 and GL+3406) are shown in Fig. 6. Both predicted and measured trends show the heat loss from the hearth gradually decreases during the shutdown, which is predominantly due to the decrease in the total heat within the hearth. During the first 100 hours of the shutdown, there is good agreement between predicted and measured results although the predicted value is somewhat lower than the measured value at the initial point. Beyond 100 hours, the increase in measured 
temperature difference is due to the start-up (blow-in) of the furnace. In the simulation, the boundary condition has not considered the heat carried by the blast as the furnace was started up, which causes the predicted results to deviate from measured results.

Heat flux through the sidewall. In Fig. 8, predicted and measured trends for the temperature difference between short and long sidewall thermocouples are shown for elevations, GL+6414 and GL+4763. At the higher elevation, GL+6414, whilst the predicted and measured data show similar trends during the 100 -hour stop, a $5^{\circ} \mathrm{C}$ difference remains. The most likely reason for this is the estimated wear of the hearth sidewall refractory. Another possible reason is that the temperature boundary condition for the extended shutdown period ( 100 hours) utilised data from a normal shutdown period ( 60 hours) and an assumed linear extrapolation beyond 60 hours, as shown in Figure 2. Finally, during the normal shutdown, burden was not run down to the tuyere level, so this can also lead to some variations in temperature measurements compared with the extended shutdown. At the lower level (GL+4763), the comparison between predicted and measured data shows intersecting trends. The initial low measured temperature difference at GL+4763 is related to the change in the cooling water temperature at the start of shutdown. The sudden change of cooling water temperature led to unsteady heat transfer. Compared to GL+6414, the response of the long and short thermocouples at GL+4763 to the sudden temperature change is a little stronger because their locations are nearer to the stave body cooling water inlet. Note that the values of temperature difference at GL+4763 are relatively small, as highlighted in Fig. 8. Over time, the measured temperature difference is higher than predicted, indicating that the hearth corner wear is also likely to be higher than assumed because the temperatures at GL+4763 are determined by the heat transfer through both the hearth corner and sidewall.

Taphole length. The taphole length serves as a means of further corroborating the model. The calculated lower and upper limits of taphole length after 96 hours of the shutdown (i.e. the finish) are $3.25 \mathrm{~m}$ and $3.65 \mathrm{~m}$, respectively. The recorded (measured) taphole lengths for the first four casting operations after the shutdown were $3.0 \mathrm{~m}, 3.2 \mathrm{~m}$, $3.4 \mathrm{~m}$ and $3.5 \mathrm{~m}$, respectively. These were all from the same taphole and it is important to note that prior to the recorded first opening time, this taphole had been opened and closed a number of times to ensure it remained clear and available for casting liquids. Therefore, the actual taphole length on the first opening was likely to be greater than $3.0 \mathrm{~m}$, due to deteriorating internal conditions.

Tapping from this single taphole also meant that nearby hearth materials (liquids, coke) would have begun to be heated as the hot liquids produced above percolated through the coke bed. However, since the tuyeres were opened sequentially over many days after start up, the limited number of opened tuyere and low liquids production rate meant that the heating rate of the hearth overall was quite slow. In fact, solidification is expected to have continued away from the operating taphole even after start-up. As such, the actual data indicated that the taphole length for the other taphole eventually used in the sequence was $3.8 \mathrm{~m}$ after 148 hours from the start of shutdown, which matched the expected length of $3.6 \mathrm{~m} \sim 4.0 \mathrm{~m}$ at Day 6 .

Overall, these taphole predictions reflect the progress of hearth cooling and provide a useful comparison with actual hearth conditions. The discrepancy as noted above is most likely linked to the specific operations associated with furnace start-up, wall boundary conditions used in the simulation and possible variations in hearth refractory wear at different circumferential locations. During the shutdown, the predicted lower 
and upper limits within the first 6 days had been provided to the operation team. These were obtained by adding the thickness of the solidification layer, i.e. $\Delta \mathrm{L}$ in Figure 6 , to the lower and upper limits during the normal operation. Together with the temperature trend in the pad and sidewall, the information guided the operation team in decision making during start-up.

\section{Conclusion}

A mathematical model of heat transfer in a BF hearth has been applied to investigate the effects of process parameters on hearth cooling during an extended shutdown of BlueScope's No. 5 Blast Furnace. The introduction of latent heat and transient boundary conditions has been constructive in the model's developments. A comparison between predicted and measured results during an extended shutdown shows that the model predictions can reasonably reflect the actual hearth conditions, including the extent of liquid iron solidification. The model also shows that heat loss through the sidewall is more significant than that through the hearth pad. Modelling of hearth cooling has provided guidelines for the estimation of taphole length, the progression of the hearth iron solidification layer and the transient variation of refractory temperatures. In terms of the taphole length and the prediction of the extent of solidification in the hearth, the proportion of hearth volume with solidified liquid iron over the $\sim 100 \mathrm{hr}$ stop of the blast furnace was calculated to be less than $10 \%$.

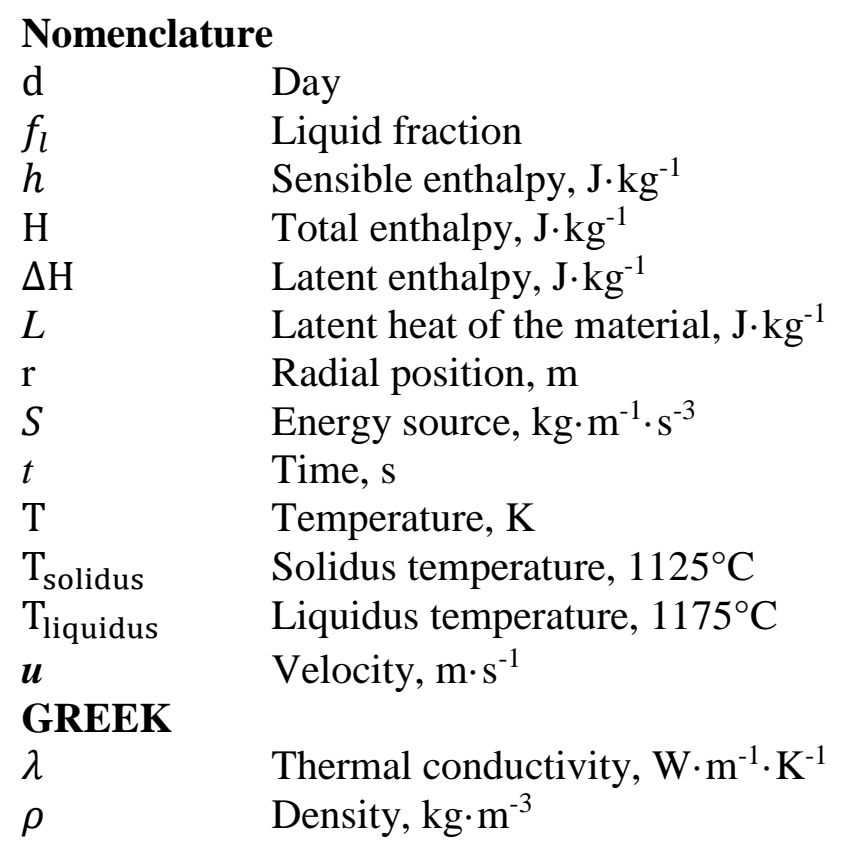

\section{Acknowledgments}

The authors gratefully acknowledge Mr. B. Kelly and Dr. M. Chapman (BlueScope Ltd) for their valuable discussions. The authors also thank BlueScope Ltd for the permission to publish the results.

\section{References}

1. Dong XF, Zulli P. Prediction of blast furnace hearth condition: Part I - A steady state simulation of hearth condition during normal operation. Ironmaking and Steelmaking. 2018 (submitted for publication).

2. Kobayashi R. Modeling and numerical simulations of dendritic crystal growth. Physica D: Nonlinear Phenomena. 1993;63(3-4):410-423. 
3. Boettinger WJ, Warren JA, Beckermann C, et al. Phase-field simulation of solidification. Annual Review of Materials Science. 2002;32:163-194.

4. Packard NH. Theory and Applications of Cellular Automata. Singapore: World Scientific; 1986.

5. Brown SGR, Bruce NB. A 3-dimensional cellular automaton model of 'free' dendritic growth. Scripta Metallurgica et Materiala. 1995;32(2):241-246.

6. López J, Gómez P, Hernández J. A volume of fluid approach for crystal growth simulation. Journal of Computational Physics. 2010;229(19):6663-6672.

7. Gibou F, Fedkiw R, Caflisch R, et al. A level set approach for the numerical simulation of dendritic growth. Journal of Scientific Computing. 2003;19(1-3):183199.

8. Sparrow EM, Patankar SV, Ramadhyani S. Analysis of melting in the presence of natural convection in the melt region. Journal of Heat Transfer. 1977;99(4):520526.

9. Crank J. Free and Moving Boundary Problems. Oxford: Clarendon Press; 1984.

10. Sullivan Jr JM, Lynch DR, O'Neill K. Finite element simulation of planar instabilities during solidification of an undercooled melt. Journal of Computational Physics. 1987;69(1):81-111.

11. Voller VR, Prakash C. A fixed grid numerical modelling methodology for convection-diffusion mushy region phase-change problems. International Journal of Heat and Mass Transfer. 1987;30(8):1709-1719.

12. Voller VR, Swaminathan CR, Thomas BG. Fixed grid techniques for phase change problems: A review. International Journal for Numerical Methods in Engineering. 1990;30(4):875-898.

13. Thomas BG, Samarasekera IV, Brimacombe JK. Comparison of numerical modeling techniques for complex, two-dimensional, transient heat-conduction problems. Metallurgical and Materials Transactions B. 1984;15(2):307-318.

14. Basu B, Date AW. Numerical modelling of melting and solidification problems-A review. Sadhana. 1988;13(3):169-213.

15. Lacroix M, Voller VR. Finite difference solutions of solidification phase change problems: Transformed versus fixed grids. Numerical Heat Transfer, Part B: Fundamentals. 1990;17(1):25-41.

16. Date AW. A strong enthalpy formulation for the Stefan problem. International Journal of Heat and Mass Transfer. 1991;34(9):2231-2235.

17. Hu H, Argyropoulos SA. Mathematical modelling of solidification and melting: A review. Modelling and Simulation in Materials Science and Engineering. 1996;4(4):371-396.

18. Voller VR, Swaminathan CR. General source-based method for solidification phase change. Numerical Heat Transfer, Part B: Fundamentals. 1991;19(2):175-189.

19. Panjkovic V, Truelove JS, Zulli P. Numerical modelling of iron flow and heat transfer in blast furnace hearth. Ironmaking and Steelmaking. 2002;29(5):390-400.

20. Wright B, Zulli P, Bierbrauer F, et al. Assessment of refractory condition in a blast furnace hearth using computational fluid dynamics. Third International Conference on CFD in the Process Industries; 10-12 December; Melbourne, Australia2003.

21. Guo BY, Maldonado D, Zulli P, et al. CFD modelling of liquid metal flow and heat transfer in blast furnace hearth. ISIJ International. 2008;48(12):1676-1685.

22. Komiyama KM, Guo BY, Zughbi H, et al. Improved CFD model to predict flow and temperature distributions in a blast furnace hearth. Metallurgical and Materials Transactions B. 2014;45(5):1895-1914. 
23. Jimbo I, Cramb AW. The density of liquid iron-carbon alloys. Metallurgical and Materials Transactions B. 1993;24(1):5-10.

24. Ražnjević K. Handbook of Thermodynamic Tables. Second ed. New York: Begell House Inc.; 1995.

25. Maldonado D, Zulli P, Guo BY, et al. Mathematical modelling of flows and temperature distributions in the blast furnace hearth. Fifth International Conference on CFD in the Process industries; 13-15 December; Melbourne, Australia2006. 
Table 1 Material properties

\begin{tabular}{|l|c|c|c|}
\hline \multicolumn{1}{|c|}{ Materials } & $\begin{array}{c}\text { Density } \\
\left(\mathrm{kg} \cdot \mathrm{m}^{-3}\right)\end{array}$ & $\begin{array}{c}\text { Heat Capacity } \\
\left(\mathrm{J} \cdot \mathrm{kg}^{-1} \cdot \mathrm{K}^{-1}\right)\end{array}$ & \multicolumn{1}{c|}{$\begin{array}{c}\text { Conductivity } \\
\left(\mathrm{W} \cdot \mathrm{m}^{-1} \cdot \mathrm{K}^{-1}\right)\end{array}$} \\
\hline $\begin{array}{l}\text { Refractory } \\
{[1]}\end{array}$ & $1560 \sim 2780$ & 1260 & $1 \sim 21$ \\
\hline Liquid iron & $\begin{array}{c}7737-0.5 \mathrm{~T} \\
{[23]}\end{array}$ & $\begin{array}{c}\text { Min }(850, \\
0.50 \mathrm{~T}+298.98)[19, \\
24]\end{array}$ & $\begin{array}{l}59.85[24] \\
1214-0.826 \mathrm{~T}\end{array} \quad \begin{array}{l}\text { if } \mathrm{T}<\mathrm{T}_{\text {solidus }} \\
\text { if } \mathrm{T}_{\text {solidus }} \leq \mathrm{T} \leq \mathrm{T}_{\text {liquidus }} \\
\text { if } \mathrm{T}>\mathrm{T}_{\text {liquidus }}\end{array}$ \\
\hline
\end{tabular}


Top liquid thermal boundary specified for initial condition and adiabatic boundary treated during transient simulation

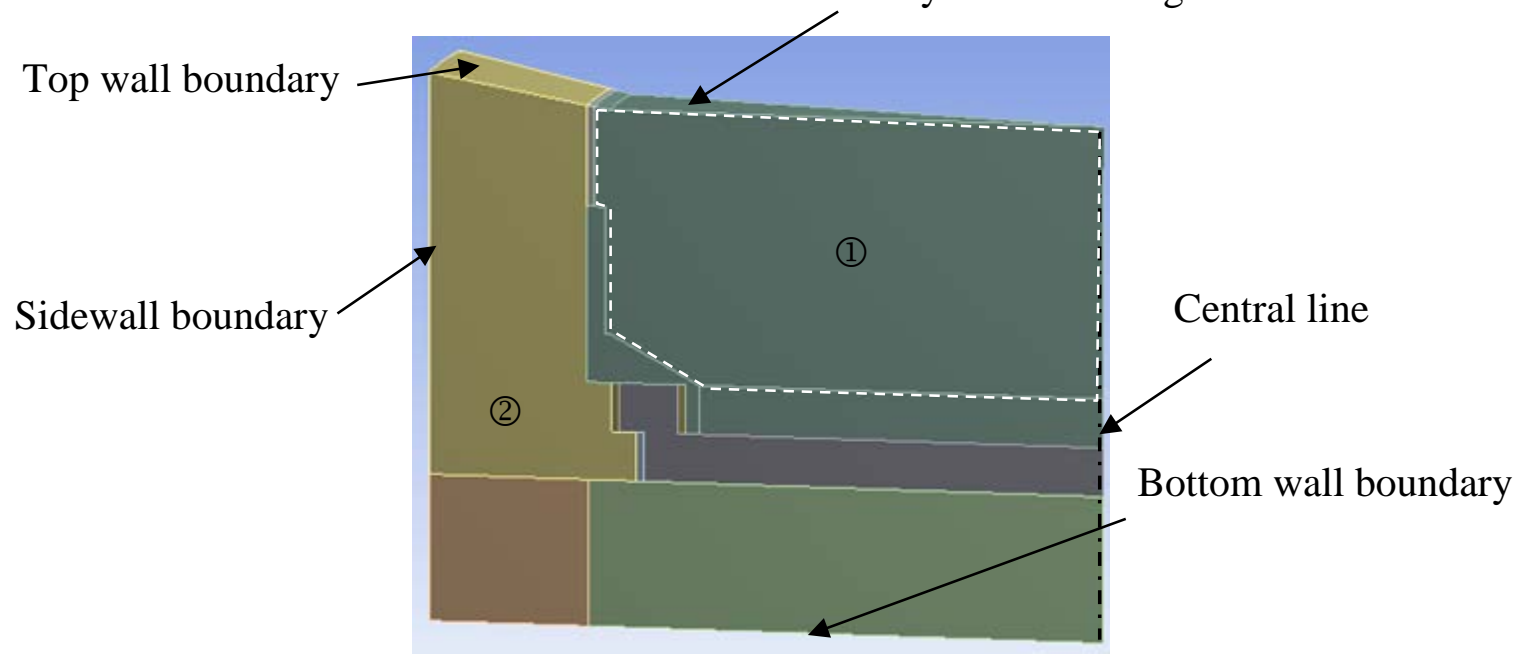

Figure 1 Computational domain used in the current simulations. (1) Liquid domain enclosed by the white dotted line; (2) Solid domain) 


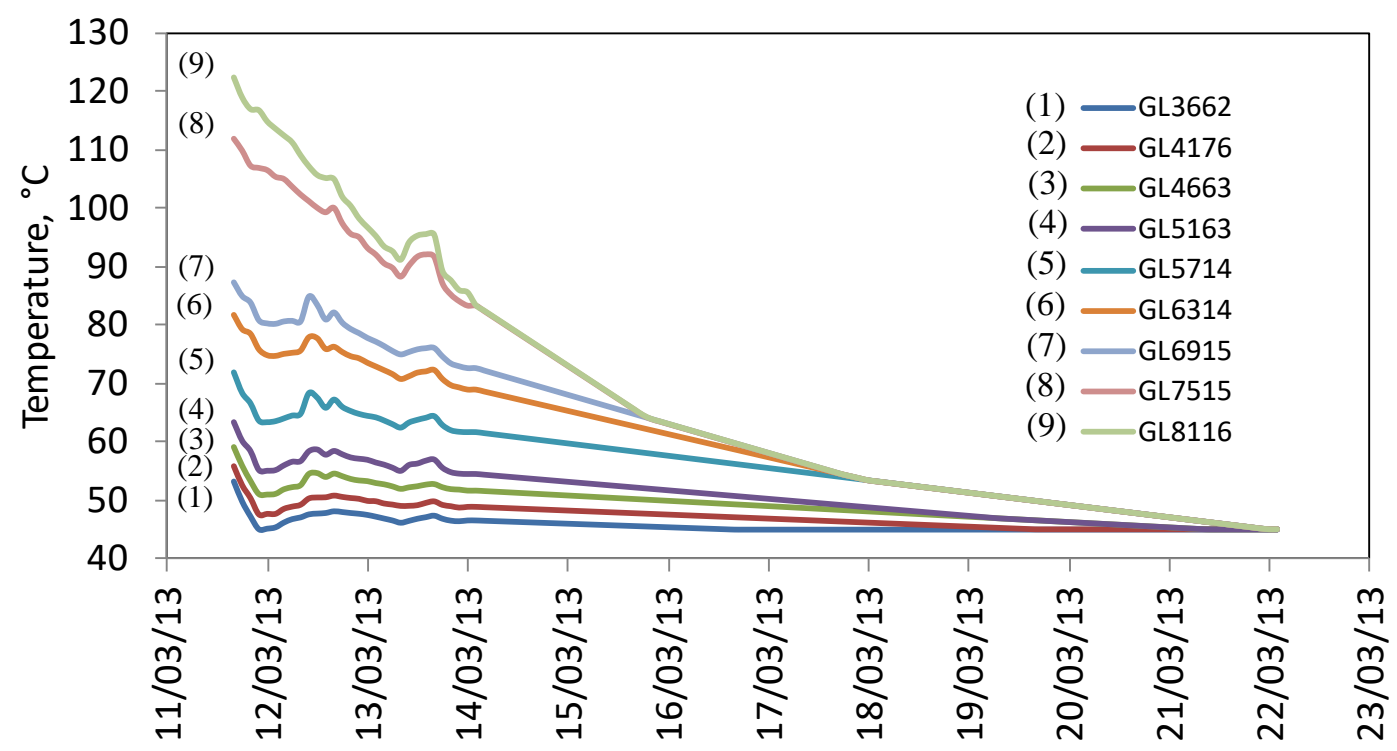

Figure 2 Transient boundary conditions for the hearth sidewall. 


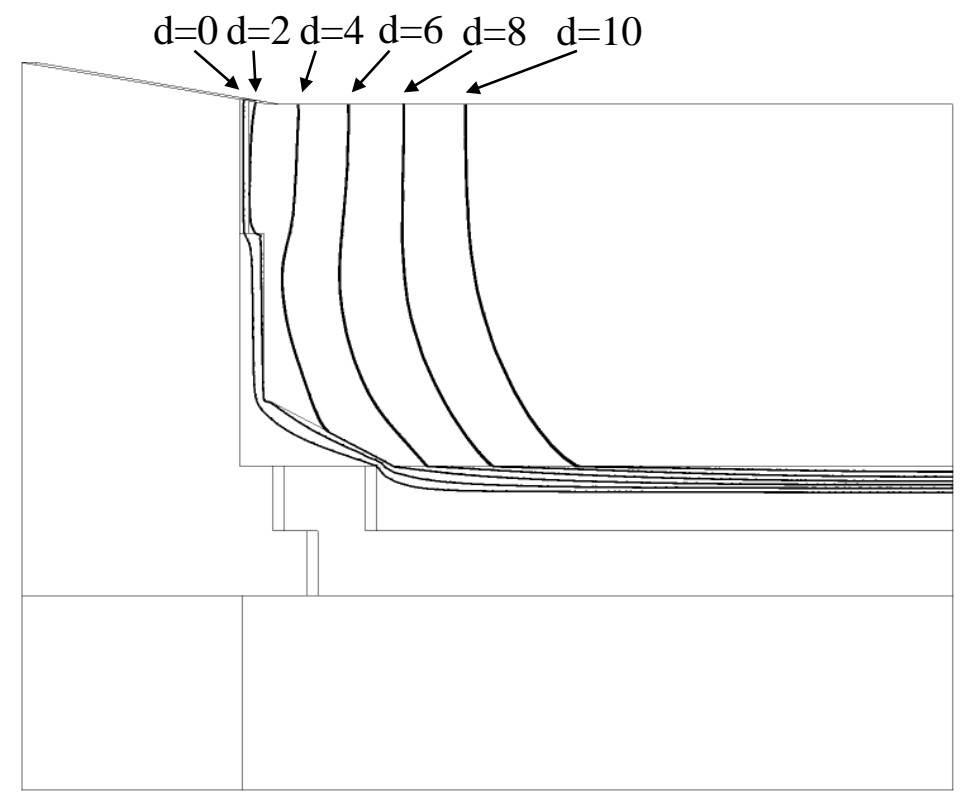

Figure 3 Evolution of $1150^{\circ} \mathrm{C}$ isotherm in the hearth over 10 days. 


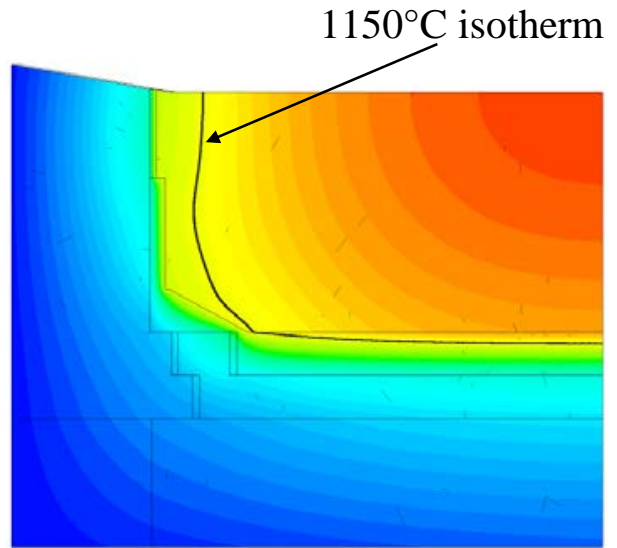

(a)

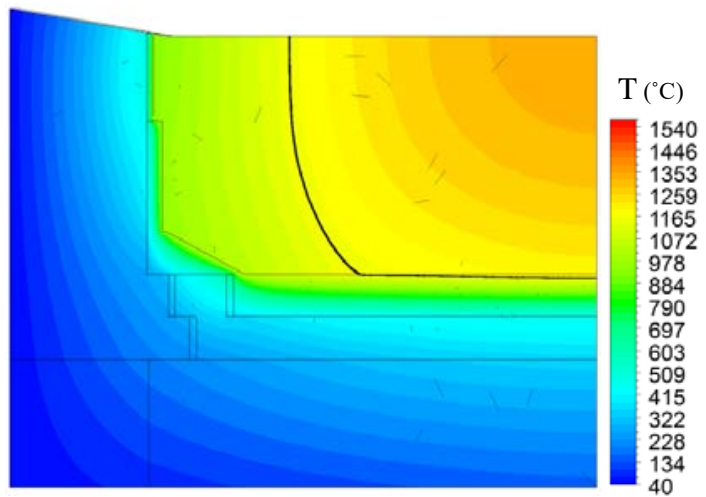

(b)

Figure 4 Temperature distribution and $1150^{\circ} \mathrm{C}$ isotherm in the hearth after (a) Day 5 and (b) Day 10. 


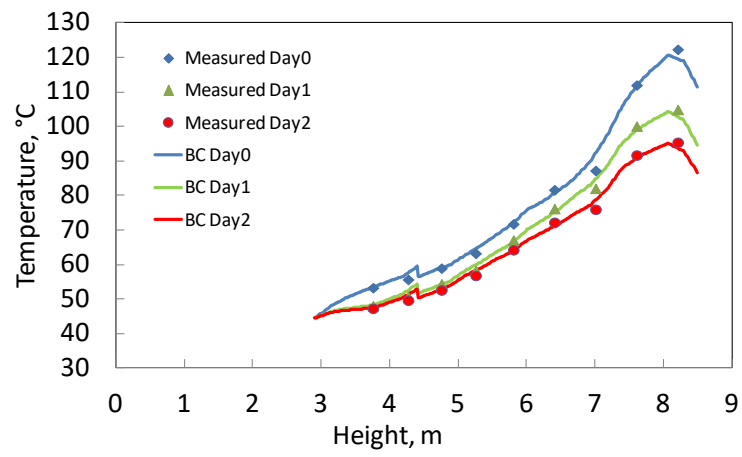

(a)

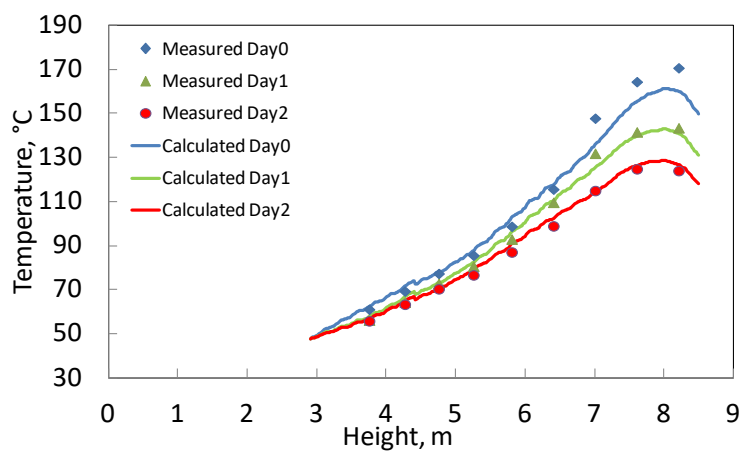

(b)

Figure 5 (a) Temperatures from short thermocouples and data used for sidewall boundary condition (BC); (b) Comparison between predicted and measured temperature at long thermocouples. 


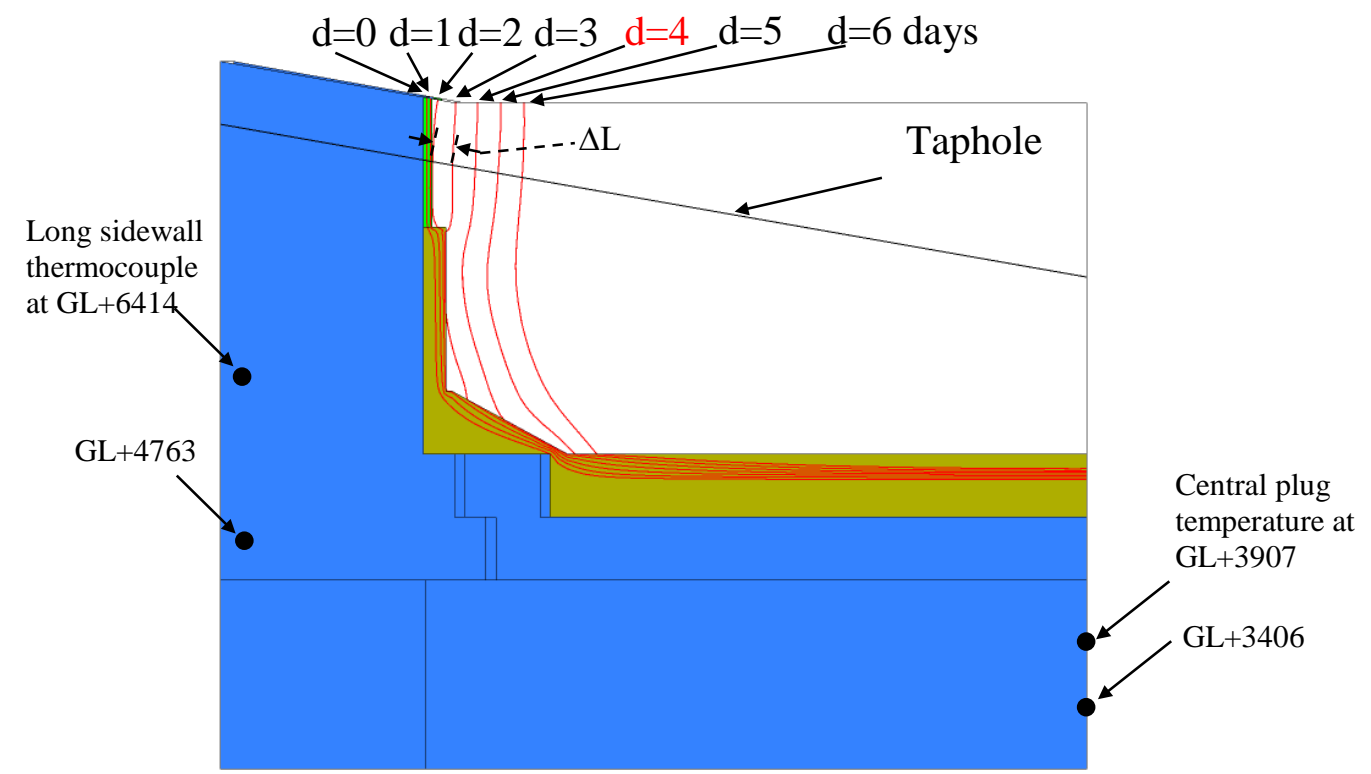

Figure 6 Predicted evolution of $1150{ }^{\circ} \mathrm{C}$ isotherm in the hearth of BlueScope's No. 5 $\mathrm{BF}$ over the first 6 days of the extended shutdown. Remaining refractories are highlighted green and olive green, respectively. 


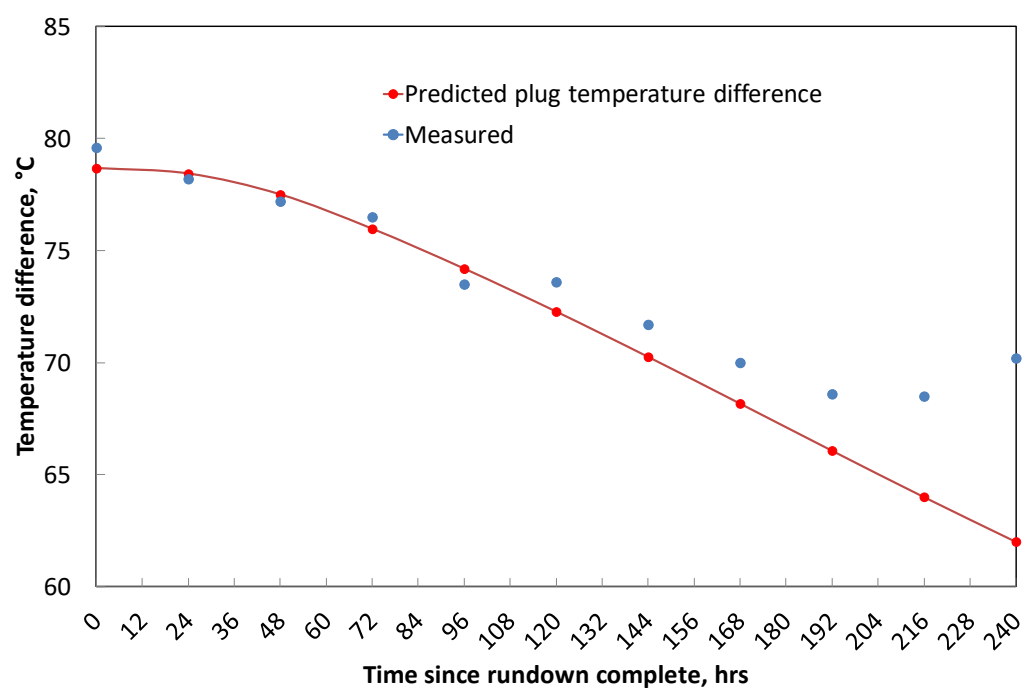

Figure 7 Temperature difference between the plug temperatures at GL+3907 and GL+3406. 


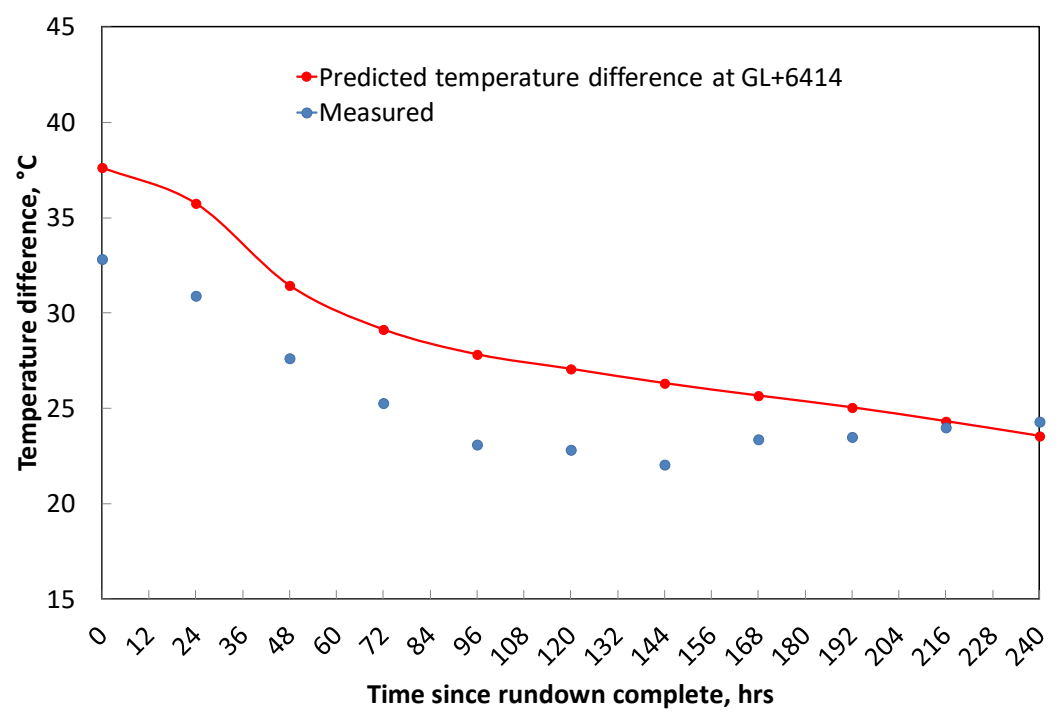

(a)

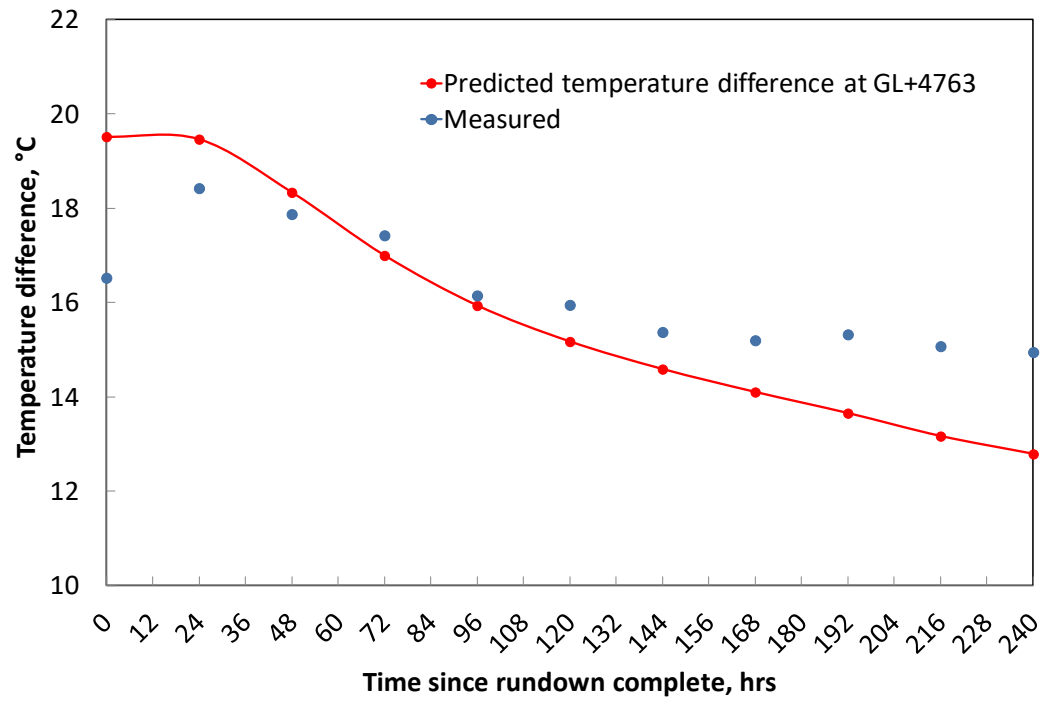

(b)

Figure 8 Temperature difference between long and short thermocouples at (a) GL+6414 and (b) GL+4763. 
A list of figure captions:

Figure 1 Computational domain used in the current simulations. (1) Liquid domain enclosed by the white dotted line; (2) Solid domain)

Figure 2 Transient boundary conditions for the hearth sidewall.

Figure 3 Evolution of $1150^{\circ} \mathrm{C}$ isotherm in the hearth over 10 days.

Figure 4 Temperature distribution and $1150^{\circ} \mathrm{C}$ isotherm in the hearth after (a) Day 5 and (b) Day 10.

Figure 5 (a) Temperatures from short thermocouples and data used for sidewall boundary condition (BC); (b) Comparison between predicted and measured temperature at long thermocouples.

Figure 6 Predicted evolution of $1150{ }^{\circ} \mathrm{C}$ isotherm in the hearth of BlueScope's No. 5 BF over the first 6 days of the extended shutdown. Remaining refractories are highlighted green and olive green, respectively.

Figure 7 Temperature difference between the plug temperatures at GL+3907 and GL+3406.

Figure 8 Temperature difference between long and short thermocouples at (a) GL+6414 and (b) GL+4763. 